\title{
OUTCOME OF CORONARY BYPASS GRAFTING
}

Sir,

We read the article 'Outcome of coronary artery bypass grafting in patients........artery disease' by Nozari et al., which was published in the October 2007 issue of the journal. ${ }^{[1]}$ It is an interesting article; and in the extant literature, one finds an endless list of articles focusing on the outcome of coronary artery bypass grafting (CABG) surgery. Under 'Material and methods,' the authors describe a stenosis of $50 \%$ or more in the left main coronary artery as significant. We would appreciate an exact anatomical location of the stenosis under such circumstances. As anatomists, we also wonder if $70 \%$ or greater than 
that can be considered as significant stenosis. It has to be spelt out in detail if there is any criterion for classifying such stenosis. The authors have mentioned in Table 5, left main disease as the risk factor. It needs to be described what they mean by 'left main disease.'

In the present-day scenario, the researchers have even identified the inflammatory markers like cardiac troponin I (cTnl), interleukin-6, SC5b-9 involved in such surgical procedures. ${ }^{[2]}$ Perhaps the atrial fibrillation occurring after the surgery is best explained by the presence of these markers. Interestingly, it has been seen that the neurocognitive dysfunction (NCD) continues to occur in a significant number of patients after cardiac procedures. ${ }^{[3]}$ It has been observed that acute renal failure is a major complication following CBAG surgery that is strongly associated with in-hospital mortality. ${ }^{[4]}$ There is a need to discuss all such complications in detail.

We would have appreciated if the authors had made some sincere efforts to link the body mass index to the mortality. There are research reports on the study of body mass index into weight classes that can influence the hospital mortality, after CABG surgery. ${ }^{[5]}$ Many factors have to be taken into consideration for the assessment of mortality and morbidity. The present study has more of statistical data and less new facts over existing literature.
Srijit Das, J. D. Chaudhuri* Department of Anatomy, U niversiti Kebangsaan Malaysia, Kuala Lumpur, Malaysia, *Department of Medical Physics, Sunnybrook Health Sciences Center, Toronto, Canada

Correspondence:

Dr. Srijit Das, Department of Anatomy, Universiti Kebangsaan Malaysia, 50300 Kuala Lumpur, Malaysia. E-mail: das_srijit23@rediffmail.com

\section{REFERENCES}

1. Nozari $Y$, Hashemlu A, Hatmi ZN, Sheikhvatan M, Iravani A, Bazdar A, et al. Outcome of coronary artery bypass grafting in patients without major risk factors and patients with at least one major risk factor for coronary artery disease. Indian J Med Sci 2007;61:547-54.

2. Immer FF, Ackermann A, Gygax E, Stalder $M$, Englberger L, Eckstein FS, et al. Minimal extracorporeal circulation is a promising technique for coronary artery bypass grafting. Ann Thorac Surg 2007;84:1515-21.

3. Puskas F, Grocott HP, White WD, Mathew JP, Newman MF, Bar-Yosef S. Intraoperative hyperglycemia and cognitive decline after CABG. Ann Thorac Surg 2007;84:1467-73.

4. Swaminathan $M$, Shaw $A D$, Phillips-Bute $B G$, McGugan-Clark PL, Archer LE, Talbert S, et al. Trends in acute renal failure associated with coronary artery bypass graft surgery in the United States. Crit Care Med 2007;35:2286-91.

5. Filardo G, Hamilton C, Hamman B, Ng HK, Grayburn P. Categorizing BMI may lead to biased results in studies investigating in-hospital mortality after isolated CABG. J Clin Epidemiol 2007;60:1132-9. 